\title{
Erratum to: Subacute onset Hirayama disease with extensive myelopathy on MRI in flexed posture
}

\author{
Merel Brems $^{1} \cdot$ Johan Van Goethem $^{1} \cdot$ Mania De Praeter $^{1} \cdot$ Barbara Willekens $^{1,2}$
}

Published online: 20 May 2017

(C) Belgian Neurological Society 2017

\section{Erratum to: Acta Neurol Belg}

DOI 10.1007/s13760-017-0782-y

Unfortunately, Figs. 1 and 2 were deleted in the original publication. Figures 1 and 2 are given below.

The original version is also updated.

The online version of the original article can be found under doi:10.1007/s13760-017-0782-y.

Merel Brems

merel.brems@gmail.com

1 Universitair Ziekenhuis Antwerpen, Antwerp, Belgium

2 Laboratory of Experimental Hematology, University of Antwerp, Antwerp, Belgium 


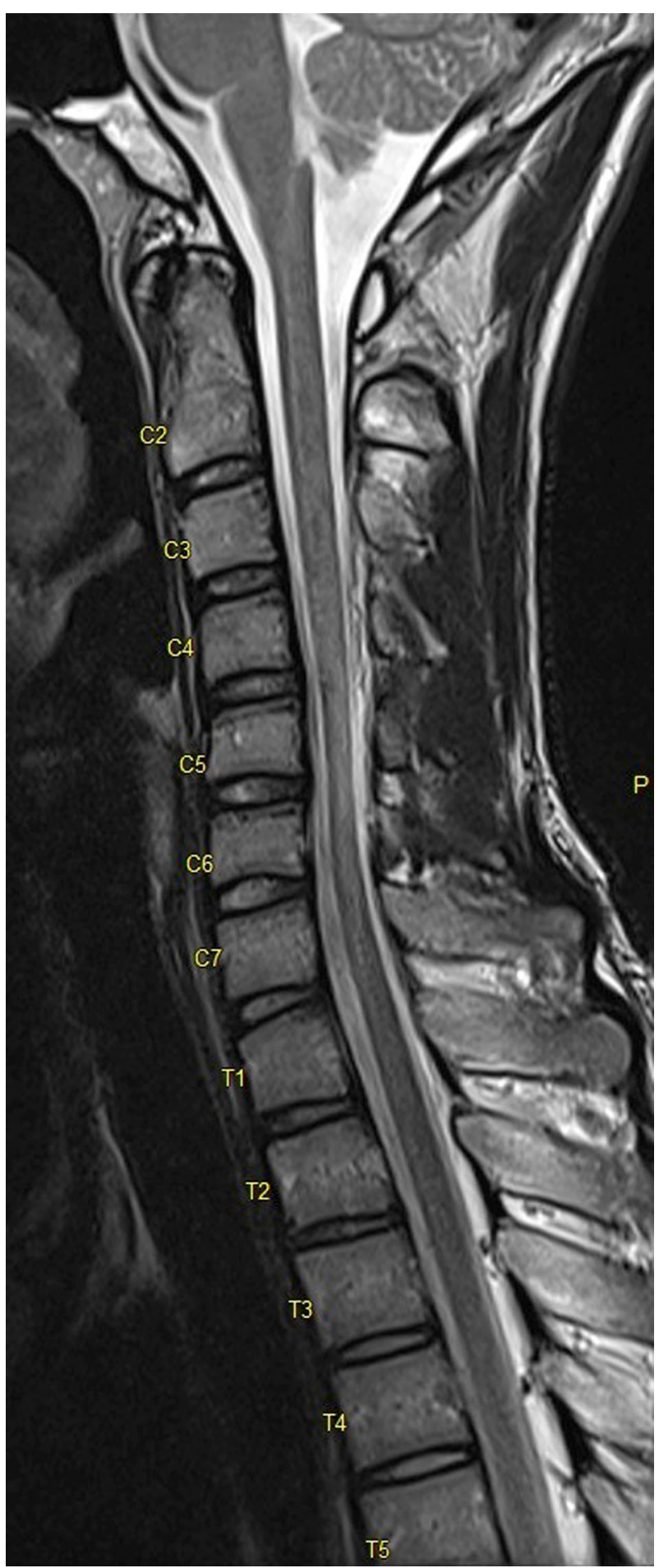

Fig. 1 A midsagittal T2-weighted MR-image shows focal medullary atrophy over the lower cervical segment from $C 4$ to $C 7$ with accompanying intramedullary $T 2$ hyperintense signal 
Fig. 2 a Midsagittal T2 and

b STIR MR-images in flexion.

These images show severe

spinal narrowing due to

compression by an anterior

displaced posterior dural lining

with a secondary broadened

posterior epidural space
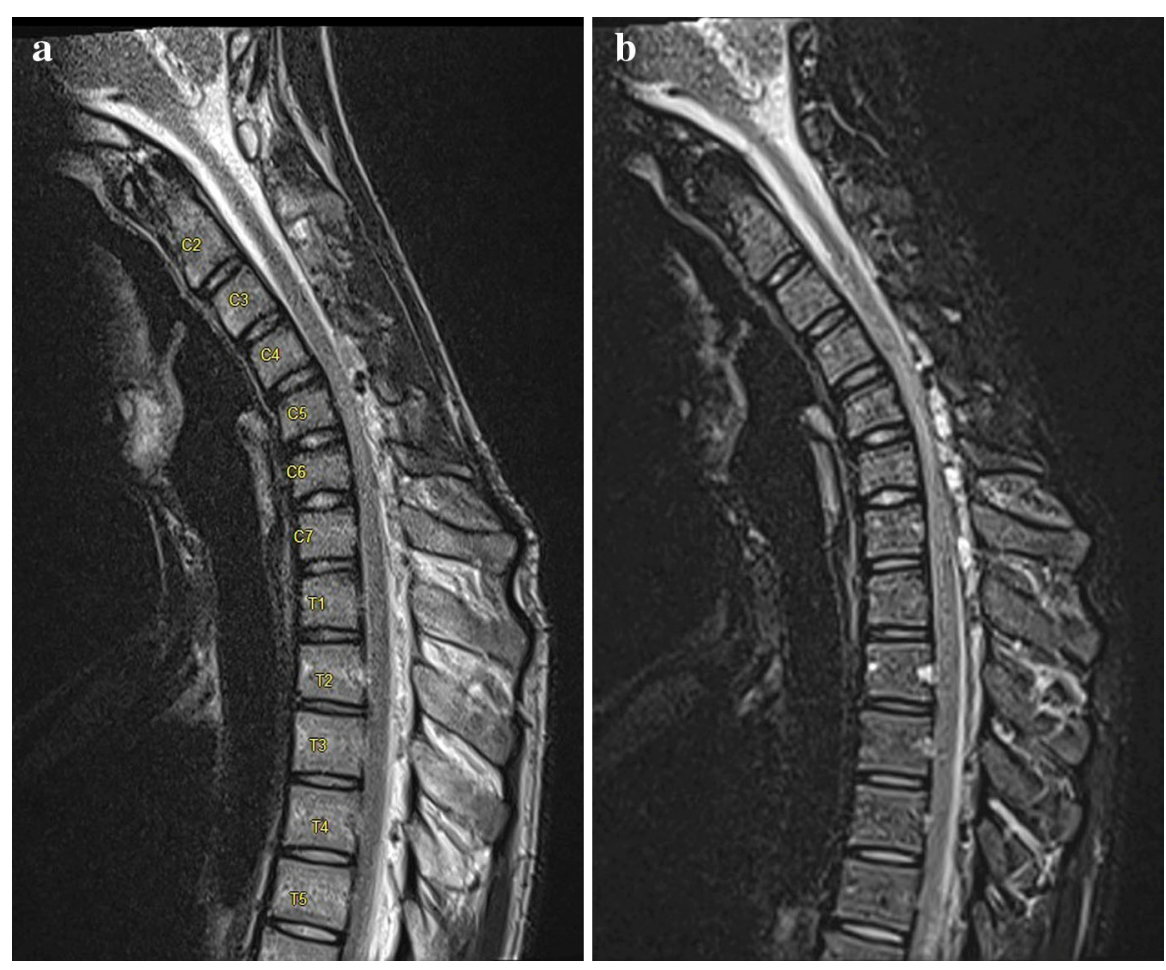